\title{
Contribuição das Âncoras de Carreira para Entender Diferenças e Similaridades de Gênero e Profissão na Geração Y
}

\author{
Contribution of Career Anchors to Understand Differences and Simila- \\ rities Between Gender and Occupation in Generation $Y$
}

http://dx.doi.org/10.5007/2178-4582.2013v47n1p152

\author{
Dione Fagundes Nunes Gomes e Leonardo Nelmi Trevisan \\ Pontifícia Universidade Católica de São Paulo, São Paulo/SP, Brasil \\ Elza Fátima Rosa Veloso \\ Faculdade Fia de Administração e Negócios, São Paulo/SP, Brasil \\ Rodrigo Cunha da Silva \\ Universidade de São Paulo, São Paulo/SP, Brasil
}

\begin{abstract}
Para investigar o impacto das variáveis "área de atuação" e "gênero" nas âncoras de carreira de pessoas da Geração Y - objetivo principal deste trabalho - foram utilizados os resultados de pesquisa descritiva, realizada com formandos do curso de administração, com idades entre 23 e 34 anos, no período de 2008 a 2011. Uma média de 140 entrevistas foram realizadas em cada ano da série. Para a identificação das âncoras utilizou-se o instrumento de Edgar Schein, com análise time lag para comparações. Gerência Geral e Criatividade Empreendedora são âncoras que se concentram no gênero masculino; e, Estilo de Vida, no feminino. Os profissionais de Finanças da Geração Y apresentaram tendência ao empreendedorismo, enquanto os de Recursos Humanos são menos propensos à âncora Criatividade Empreendedora. Profissionais de $\mathrm{RH}$ da Geração Y, porém, apresentam predisposição à âncora Inovação em Produtos e Serviços.
\end{abstract}

Palavras-chave: Geração Y - Âncoras de carreira - Gênero.
In order to investigate the impact of the Generation Y career anchors'variables, such as practice areas and gender - the main goal of this paper - we used the findings of a descriptive research conducted across the years 2008 to 2011 with Business course undergraduate students aged 23 to 34 years. An average of 140 interviews were held in every year of the series. For a proper identification of the anchors, Edgar Schein's tool for data colection was applied, as well as the time lag analysis for comparisons among subjects. Masculine gender concentrates General Management and Entrepreneurial Creativity anchors, while Lifestyle is more often on the feminine gender. There is a trend of Finance professionals of Generation $Y$ towards entrepreneurship, while Human Resources professionals are less prone to the Entrepreneurial Creativity anchor. HR professionals of Generation $Y$, however, are predisposed to the anchor of Innovation in Products and Services.

Keywords: Generation Y - Career anchors - Gender.

\section{Introdução}

Desde o final do século XX, indivíduos e organizações depararam-se com um cenário econômico marcado pela concorrência global e sem espaços para perenidades. Nos tempos atuais, ao contrário, a ideia de flexibilidade é quase venerada como uma das grandes respostas fortemente marcadas pela urgência 
das mudanças e por prazos cada vez mais curtos. Os desdobramentos desse fato atingem, inexoravelmente, a gestão de carreira, que deixou a marca das relações duradouras entre indivíduos e organizações (ARTHUR \& ROUSSEAU, 1996) e passou a assumir novos contornos, com novas formas de desenvolvimento profissional (CHANLAT, 1995).

Assim, assistiu-se à intensa transferência de responsabilidade sobre a carreira da empresa para o indivíduo ou, no mínimo, da divisão dessa responsabilidade, como observou Dutra (1992). Motivado pela necessidade de adequação às demandas e exigências do mercado e pela drástica redução dos vínculos formais de trabalho, o indivíduo assume a maior parcela da responsabilidade sobre seu desenvolvimento profissional.

Significativas contribuições podem ser apontadas no sentido de entender o universo que envolve a gestão de carreira. Tais contribuições envolvem o conceito de carreira (DUTRA, 1992; SCHEIN, 1996; HALL, 2002; COELHO, 2006; DUTRA, 2006), e mecanismos de análise da gestão de carreira, como por exemplo as carreiras inteligentes (QUINN, 1992; ARTHUR, CLAMAN, DEFILLIPI, 1995), passando pela identidade e trajetória profissionais (IBARRA, 2009; VELOSO, DUTRA, 2010), e pelo conceito de âncoras de carreira (SCHEIN, 1996). Este último evidencia seu valor na medida em que norteia as decisões e escolhas profissionais.

Em texto adaptado por Dutra e Albuquerque (USP, 2002), a âncora de carreira, tal como Edgar Schein a apresenta, é uma combinação das áreas percebidas de competência, motivos e valores que a pessoa não abandonaria mesmo diante de escolhas difíceis. No entanto, é preciso ter presente que "âncoras" representam formas de "conhecer" interesses, definindo modos de relação com o trabalho, consistindo em significativo instrumento de autoconhecimento, embora sem reunir especificações de instrumento para diagnosticar adaptação a áreas de trabalho.

O universo de carreiras também permite outros olhares que avançam no entendimento das nuances presentes. Entender os processos afins à carreira sob as lentes do gênero (HOFFMANN, 2004; VIEIRA, 2005) e das gerações (LIPKIN; PERRYMORE, 2010; VASCONCELOS, 2009) é um bom exemplo dessas possibilidades. Neste artigo, essas duas formas de análise são consideradas e fazem parte do objetivo principal que norteou a pesquisa: investigar o impacto da área de atuação profissional e do gênero nas âncoras de carreira de pessoas da Geração Y. Com esse propósito, foram utilizados os resultados de uma pesquisa realizada com formandos do curso de administração de uma universidade privada da cidade de São Paulo, no período entre 2008 e 2011.

Para cumprir esses objetivos, este artigo é dividido em três seções. Na primeira, além do conceito de carreira, a revisão da literatura aborda a visão sobre as âncoras de carreira, trajetória de carreira, gênero e gerações; na segunda seção os procedimentos metodológicos são detalhados; e, na terceira, os resultados da pesquisa são apresentados e analisados. 


\section{Revisão de literatura}

\section{Conceito de carreira}

Pela falta de univocidade, é possível observar o uso do termo carreira em diferentes abrangências e significados. Coelho (2006) fornece pistas do uso associado ao caminho percorrido por alguém durante sua vida e do uso relacionado ao trabalho, profissão ou atividade profissional num contínuo exercício. Nesta última linha, Dutra defende a ideia de que "a carreira não deve ser entendida como um caminho rígido a ser seguido, mas como uma sequencia de posições e de trabalhos realizados pela pessoa" (DUTRA, 2006, p. 102) . Para este autor, dois aspectos caracterizam o conceito de carreira: o primeiro diz respeito à carreira enquanto espaços sucessivos que a pessoa assume ao longo da vida profissional; o segundo refere-se a "(...) atribuição da responsabilidade por administração de carreiras tanto à empresa como ao indivíduo" (DUTRA, 1992, p. 65).

Paralelamente, Arthur, Hall e Lawrence (1989) afirmam que, no início dos anos 1970, ainda não existia um campo estabelecido para a análise das carreiras nos estudos das organizações e da gestão. A principal base teórica na época era proporcionada pelos psicólogos vocacionais e sociólogos. Dessa forma, torna-se relevante, além da visão da Administração, enfatizar também contribuição da Psicologia na formação de conceitos relativos à carreira. Ribeiro (2009) destaca o fato de que o constructo carreira é teórico-prático, formado por duas dimensões interligadas: a administrativa e a psicossocial.

Segundo Hall (2002, p.12), o conceito de carreira, tanto no conhecimento popular quanto no científico, possui quatro significados distintos, sendo:

1. Carreira como avanço: é o conceito que flui livremente pela sociedade, normalmente entendido através de uma noção de mobilidade vertical, subindo de cargo numa organização;

2. Carreira como profissão: nesse conceito, também bastante difundido popularmente, considera-se somente determinados trabalhos como fruto de uma carreira, em geral profissões que elegem algum status ao indivíduo, como advogados, médicos, executivos;

3. Carreira como sequência de trabalhos realizados: nesse conceito, muito aceito dentro da comunidade que estuda o comportamento social, todo e qualquer trabalho realizado pelo indivíduo constitui a sua carreira.

4. Carreira como sequência de experiências relativas a uma função: essa definição, também bastante influente para quem estuda o comportamento social, a carreira representa a forma como a pessoa experimenta a sequência de trabalhos e atividades que constituem sua história profissional. 
Hall (Ibid.) sintetiza essas observações afirmando que carreira baseiase na percepção do indivíduo acerca de suas atitudes e comportamentos em conjunto com experiências relacionadas ao trabalho, ao longo da vida. Para London e Stumph (1982), carreira envolve os trabalhos realizados durante a vida de uma pessoa, submersos numa série de acontecimentos entre as necessidades individuais, organizacionais e sociais. Na perspectiva do indivíduo, há o entendimento e a avaliação de sua experiência profissional; já a perspectiva da organização engloba políticas, procedimentos e decisões ligadas à carreira na empresa. Essas duas perspectivas são conciliadas por constantes ajustes.

$\mathrm{O}$ desenvolvimento da carreira de um indivíduo obedece a expectativas pessoais e, muitas vezes, a conjunturas impostas pela sociedade e pelas organizações, devendo o estudo desse tema considerar fatores de imprevisibilidade. Nesse sentido, segundo Dutra (1996), a definição de carreira de London e Stumph é fundamental, pois não a trata como uma sequência linear de experiências e trabalhos, mas sim, como uma série de estágios e transições que variam de acordo com as pressões sobre o indivíduo, sejam elas originadas dele mesmo ou da organização. Além disso, pondera o conceito de carreira como resultado da relação entre a pessoa e a organização, admitindo a ocorrência de movimento de carreira.

Com base no conceito construído por Hall (2002), definiu-se a visão de carreira para este estudo. Ou seja, o conceito de carreira deve ser focado na experiência subjetiva do indivíduo, na forma como ele constrói sua carreira, nas relações que estabelece com cada trabalho na vida, observando igualmente os aspectos subjetivos e objetivos, assumindo, inclusive, os altos e baixos como parte natural desse processo.

\section{Ancoras de carreira}

O conceito "âncora de carreira" tem sua origem no estudo de Edgar Schein, que buscou o aprimoramento em análises referentes à evolução de carreiras administrativas. O estudo de Schein, desenvolvido de 1961 a 1973, envolveu quarenta e quatro alunos do programa de Mestrado da Escola Sloan de Administração do MIT (Massachusetts Institute of Technology), e foi realizado com o propósito de reunir conhecimentos sobre a construção dos valores que acompanham um indivíduo em sua atividade profissional. Para esse fim, Schein efetuou entrevistas com os alunos formandos do programa e após a conclusão (em seis meses, 1 ano, 5 e 10 anos), em seus locais de trabalho. Durante esse período de estudos, as mudanças ocorridas nas carreiras foram observadas criticamente, bem como seus respectivos motivos e/ou atribuições, valores e atitudes.

Das análises extraídas, surgiram conclusões referentes à evolução interna de carreira e o conceito metafórico de "âncora de carreira", que sugere a tendência do profissional - quando em situação de desajuste com seus valores, atitudes e objetivos - de retornar a uma situação de conforto com sua autoimagem. Os indivíduos que tentavam outros empregos que não aqueles aos 
quais se adequavam, de acordo com o relato de Schein (1996), frequentemente referiam-se à imagem de retorno, de volta àquelas atividades que lhes eram mais e melhor ajustadas.

Entre os anos de 1979 e 1982, Edgar H. Schein e T. J. Delong conduziram um trabalho que resultou na identificação de oito categorias de inclinações profissionais - ou âncoras de carreira - com base neste e noutros estudos subsequentes. Para Schein (1996), a inclinação profissional (ponto de referência) do indivíduo é tão importante que, além de não descartá-la - mesmo em situações de crise - ele define sua autoimagem em função da área que predominará em sua carreira. As características gerais de cada tipo de inclinação profissional (conjunto de autopercepções relativas a talentos, habilidades e atitudes, baseadas nas experiências efetiva e individualmente vividas) são retratadas a seguir.

- Competência Técnica / Funcional (TF) - Nesta âncora, o profissional adquire o senso de identidade através da aplicação de suas habilidades técnicas. A realização profissional vem através da possibilidade de enfrentar desafios em áreas técnicas;

- Competência Gerência Geral (GG) - Pessoas ancoradas nesta competência integram uma minoria dos profissionais. O profissional orientado para a gerência geral possui a capacidade de realizar um contrato psicológico com a organização; assim, o sucesso da organização será o seu sucesso;

- Autonomia / Independência (AI) - Neste grupo, encontram-se as pessoas que possuem um nível reduzido de tolerância às regras estabelecidas por outras pessoas, por procedimentos e outros tipos de controle que venham a cercear a sua autonomia;

- Segurança / Estabilidade (SE) - Nesta âncora, a principal preocupação é a sensação de bem-estar gerada pela baixa volatilidade na sua carreira. Para isso, o profissional aqui ancorado irá guiar suas decisões de carreira pautando-se pela segurança e estabilidade;

- Criatividade Empreendedora (CE) - Neste grupo estão aqueles profissionais focados na criação de novas organizações, serviços ou produtos;

- Serviço / Dedicação a uma Causa (SD) - Nesta âncora não há renúncia, em qualquer hipótese, a trabalhos que sejam condizentes com os valores pessoais do profissional;

- Puro Desafio (DP) - A busca incessante por superação de obstáculos aparentemente impossíveis e a solução de problemas insolúveis definem o sucesso para os profissionais aqui ancorados; 
- Estilo de Vida (EV) - Nesta âncora, o profissional busca encontrar uma forma de integrar as necessidades individuais, familiares e as exigências de carreira.

À medida que os indivíduos se autopercebem e somam conhecimento sobre suas preferências profissionais, tornam-se aptos a fazer escolhas mais conscientes (DUTRA, 1996). Ainda sobre o conceito de âncora de carreira, Dutra destaca sua importância porque "influencia escolhas, afeta decisões para a mudança de um trabalho/emprego para outro, determina visões do futuro, influencia a escolha de ocupações específicas e afeta as reações do indivíduo frente ao trabalho" (DUTRA, 2010, p. 7) .

Em termos práticos, diversos estudos empíricos utilizam o instrumento de Schein em contextos diferenciados. Como exemplo de tal instrumentalidade do inventário das âncoras de carreira, o estudo recente de Cabral, Kilimnik e Veloso (2013) mostrou que a apuração das âncoras no momento da contratação de jovens engenheiros recém-formados é relevante para medir inclinações relativas ao trabalho. Contudo, as autoras sugerem que as constatações iniciais sejam submetidas a revisões periódicas, uma vez que a âncora predominante na fase de seleção, entre 15 candidatos, foi Desafio Puro, mas após 9 meses, em condições de expatriação e confinamento em canteiros de obras, tal âncora passou a compartilhar a primeira posição com Estilo de Vida e Competência Técnica Funcional.

\section{Trajetória de carreira}

Os estudos de Ribeiro (2009, p. 214) indicaram a "delimitação da trajetória de carreira como um constructo teórico-prático, que partiu de um padrão mais normativo e estável (carreira como produto) para atingir uma forma mais relacional e psicossocial (carreira como processo)". No esforço de esclarecer o significado da carreira, Veloso e Dutra (2010) referem-se a Hughes e Coser (1994) para apontar a dimensão subjetiva da carreira, composta pelas experiências particulares no trabalho que consideram as mudanças de aspirações, padrões de satisfação, autoconcepções e outras atitudes voltadas para o seu trabalho e à sua vida.

Concordando com Schein, Dutra afirma que as "pessoas tendem a permanecer em atividades profissionais de mesma natureza" (2010, p. 65), o que ele chama de "trajetória de carreira". Se a pessoa permanece na mesma trajetória, ela se desenvolve mais rápido; entretanto, caso ela mude sua trajetória, terá de lidar com outras complexidades - dentre elas, a alteração da identidade profissional. O autor utiliza a metáfora de "trocar de pele" para explicar o quão doloroso e difícil é esse processo.

Quanto à identidade profissional, Ibarra (2004) afirma que, durante os anos de trabalho, tal identidade se transforma gradual e naturalmente e que as 
pessoas nem sempre estão conscientes desse processo. Segundo a autora, não se pode mudar de forma simples de uma antiga para uma nova identidade profissional. Mudanças de carreira redefinem nossa identidade e nesse momento ocorre uma reconfiguração de possibilidades.

\section{Gênero, trabalho e carreira}

As diferenças entre homens e mulheres podem ser delineadas por aspectos socioculturais e históricos. Estes aspectos, condicionados até por questões biológicas, definem características distintas de gênero, que podem marcar comportamentos diferenciados. Na perspectiva de Hoffmann, a mulher, “[...] por sua finalidade reprodutiva, de conservação e desenvolvimento da vida, é mais sensível ao universo simbólico e espiritual da espécie humana”, enquanto o homem "que complementa o ciclo reprodutivo da espécie, está mais relacionado ao plano físico, tem mais agressividade e está inclinado a correr riscos" (HOFFMANN, 2004, p. 23). As relações de gênero, na visão desta autora, são "o pilar da cultura da sociedade de classes" e a questão de gênero é "determinante para a definição de papéis, comportamentos, direitos e deveres relacionados às esferas da vida: a produção (de bens e serviços) e a reprodução da vida (dos seres humanos, da sociedade)" (Ibid., p. 23)

A influência dos aspectos socioculturais e históricos no direcionamento de carreira de homens e mulheres está presente na organização no processo de gestão de pessoas. Hirata (2002) demonstrou, em profundidade, a importância das questões de gênero em todas as fases de reestruturação produtiva da empresa. Neves (2004) analisou a relevância da diferença de gênero nas novas configurações do trabalho. Para essas autoras, é possível perceber que o avanço tecnológico, ou as condições de trabalho mais flexíveis, não eliminaram a questão de gênero no ambiente profissional.

Wainberg (2004, p. 10), afirma que a divisão sexual de tarefas, no decorrer da história, adquiriu "contornos específicos perpassados por relações de poder e dominação". Paralelamente, observa-se o fato de que, em diferentes contextos profissionais construídos sobre diferentes culturas, os papéis masculino e feminino podem ser assumidos de maneira inversa, como exemplifica Vieira:

Na ex-União Soviética, a profissão de médico era preenchida por mulheres, assim como a de dentistas na Bélgica ou a de comerciantes na África Ocidental, mas, ao contrário, as funções de secretárias eram exercidas, em sua maioria, por homens no Paquistão. Na Holanda, do mesmo modo, há elevada proporção de enfermeiros homens e no Japão não existem praticamente mulheres na função de dirigentes de empresas, enquanto nas Filipinas e na Tailândia isso é bastante comum.(VIEIRA, 2005, p. 230): 
Na nova realidade do mundo do trabalho, características como objetividade, perseverança, estilo cooperativo, disposição de trabalhar em equipe e de dividir decisões, e uso de intuição na análise e solução de problemas marcam aspectos que facilitam a conquista pelas mulheres de atividades profissionais antes exercidas apenas por homens. A demanda por flexibilidade e ambiente de cooperação abriu espaço para a percepção de que "Na verdade, o jeito feminino de administrar não é superior ou substituto do modelo masculino, mas complementar" (GOMES, 2005, p. 7). Essa complementaridade é não apenas pretendida, mas exigida pela organização, em busca de efetiva competitividade de mercado.

No Brasil, a composição do mercado de trabalho vem se modificando ao longo dos últimos anos e a crescente presença feminina bem como seus níveis de escolaridade são fortes indicativos de alterações nos sistemas de valores sociais - sistemas esses que podem impactar o processo de escolha de carreira (SANTOS; ABRAHIM, 2008). Dados comparativos entre 2003 e 2011, divulgados pelo IBGE (2012), indicam um crescimento da presença feminina no mercado de trabalho em diferentes atividades, e também a sua primazia no índice de escolaridade. Todos os comparativos são estabelecidos entre homens e mulheres. Nos gráficos a seguir, os valores são explicitados para melhor visualização.

Gráfico 1. Participação na população ocupada, por grupamentos de atividades, segundo o sexo (\%) - (2003 e 2011)*

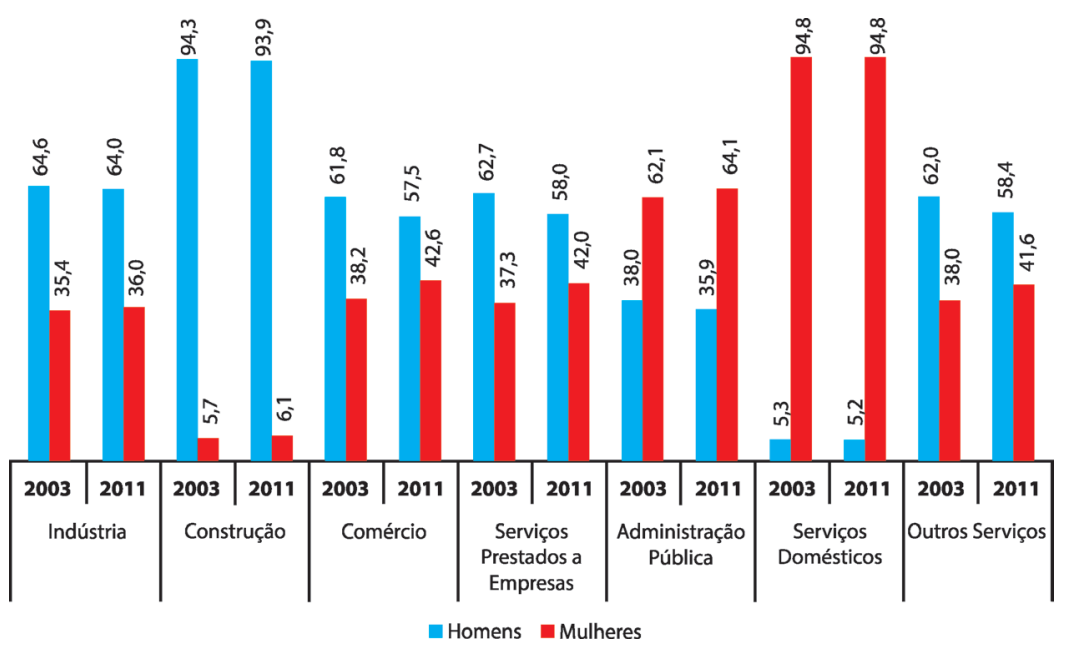

Fonte: IBGE (2012)

*Média das estimativas mensais 
Gráfico 2. Participação da população ocupada com nível superior completo, por grupamento de atividade, segundo o sexo (\%) - (2003 a 2011)*

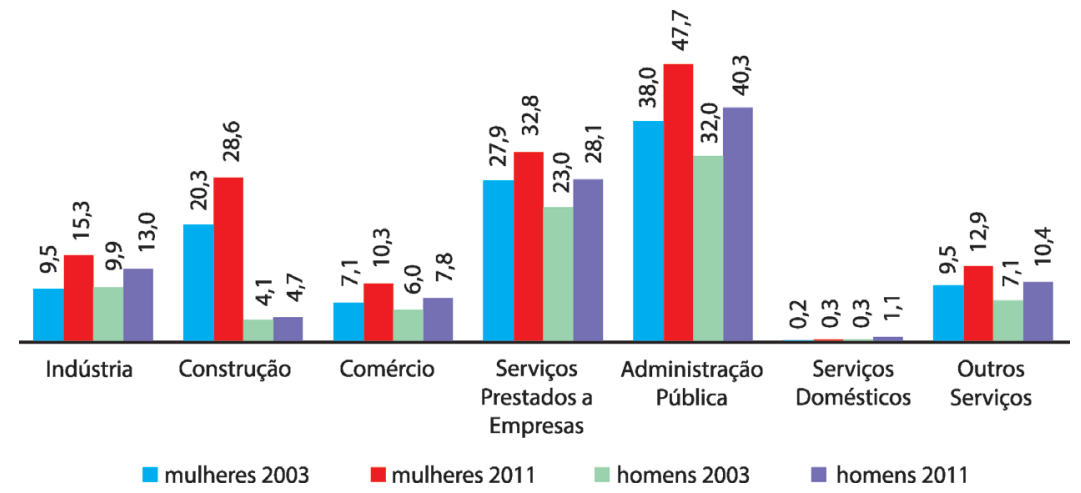

Fonte: Extraído de IBGE (2012)

- Média das estimativas mensais

Finalizando, vale destacar que Schein (1996) faz algumas observações sobre a possível influência do gênero na âncora de carreira de uma pessoa, indicando inclusive que a Âncora "Estilo de Vida" parecia predominante entre as mulheres. Apesar desta observação não ter sido feita a partir de estudos sobre a realidade brasileira, a pesquisa realizada com formandos do curso de Administração poderá fornecer subsídios para uma análise mais adequada.

\section{Gerações e carreira}

O contexto organizacional atual é marcado por muitas diversidades; dentre elas, destaca-se a que se refere à idade. No mapa funcional da maioria das organizações, é possível perceber várias gerações interagindo, cada qual com suas características e comportamentos peculiares. Apesar de haver divergência entre os autores quanto à fixação dos períodos que compreendem cada geração, neste artigo, assume-se a posição de Veloso, Silva e Dutra (2011) que definem como geração baby boomers os nascidos entre 1946 e 1964; como geração X, os nascidos entre 1965 e 1979; e, como geração Y (também chamada de geração internet ou geração da tecnologia), os nascidos a partir de 1980. Há uma quarta geração, anterior a todas essas, cuja representatividade nas organizações é menor pois, por conta da idade, já contempla o benefício da aposentadoria trata-se da geração de veteranos (os nascidos entre 1925 e 1945).

Cada geração, por seu contexto histórico, guarda especificidades no que concerne aos valores no trabalho. Neste estudo, será tratada apenas a relação entre as âncoras de carreira e a geração Y no contexto brasileiro. Quando as 
pessoas dessa geração começaram a nascer, encontraram o Brasil passando por grande instabilidade econômica, na década de 1980 e início dos anos 1990 e, pouco depois, reinstalando e consolidando a economia e a democracia. O cenário socioeconômico pode ser descrito pela cultura da não-permanência e pela falta de garantias, com mercados voláteis, além da crescente incorporação da tecnologia da informação e comunicação no cotidiano das pessoas, com a criação e rápida expansão da internet, nos anos 1990 e 2000 (COIMBRA, SCHIKMANN, 2001; MARTIN, TULGAN, 2006). A abertura econômica e o controle da inflação marcam um novo estágio de desenvolvimento brasileiro. Nas empresas, as palavras-chave são "competitividade" e "empregabilidade". Essas características se tornam ainda mais refinadas no início do século XXI, com novas demandas: a convergência das tecnologias, a mobilidade e a explosão das redes sociais.

Quanto aos valores, Smola e Sutton (2002) salientam as suas diferenças em relação às anteriores. Como principais características da Geração Y, podese ressaltar o fato de ser apreciadora da liberdade e da velocidade (TAPSCOTT, 2009), preferir esquemas mais flexíveis de trabalho, a fim de dispor de tempo para dedicação aos objetivos pessoais (TWENGE et al , 2010), e por buscar crescimento na rápido na carreira (CENNAMO, GARDNER, 2008; ZEMKE; RAINES, FILIPCZAK, 2000).

Segundo Edmunds e Turner (2005), determinadas gerações podem transformar sobremaneira os contornos do mundo do trabalho ou serem passivas às mudanças impostas pelo ambiente. Em face disso, pode-se justificar a relevância de se analisar as âncoras de carreiras da Geração Y, por ser uma geração ativa no contexto atual. Por tratar-se de uma pesquisa de levantamento, não foram levantadas hipóteses para este estudo. Porém, de acordo com o referencial teórico aqui apresentado, é possível supor que, entre os profissionais da Geração Y, há variações em suas orientações de carreira, conforme gênero e profissão.

\section{Procedimentos metodológicos}

Para investigar o impacto das variáveis "área de atuação" e "gênero" nas âncoras de carreira de pessoas da Geração Y foram utilizados os resultados de pesquisa descritiva, realizada com formandos do curso de administração, no período entre 2008 e 2011, em uma universidade privada da cidade de São Paulo.

A pesquisa descritiva tem, entre suas finalidades, o levantamento de opiniões, atitudes e crenças de uma população (GIL, 1999), tendo sido realizada por meio da aplicação de questionários padronizados, tratados de forma quantitativa. Para a identificação da âncora de carreira dos indivíduos, utilizou-se o instrumento de Edgar H. Schein. A abordagem dos formandos e a coleta de dados obedeceram a um cronograma de aplicação, previamente elaborado junto aos professores do curso que ministravam aulas às turmas de concluintes, de modo que todas as turmas fossem alcançadas. Uma vez definidas as datas e 
os horários de aplicação para cada turma, os pesquisadores compareceram pessoalmente às salas de aula e aplicaram os questionários, garantindo, desta forma, o maior número de respondentes possível.

Este questionário possui 40 questões e permite a atribuição de uma nota de 1 a 6 para cada âncora. Os dados foram obtidos por meio da aplicação do instrumento por quatro anos seguidos: 2008 (99 respondentes); 2009 (131 respondentes); 2010 (263 respondentes); e 2011 (223 respondentes). A média de idade dos respondentes foi de 22 anos e o desvio padrão de 1,82. A maior idade foi de 28 anos e, a menor, de 19 anos. Portanto, em 2011, ano de encerramento da pesquisa, o respondente de maior idade nasceu em 1983, dentro da faixa etária de nascimento tradicional da geração Y. Cerca de $40 \%$ do total de indivíduos pesquisados são homens e $60 \%$ mulheres. Quanto à atuação profissional, $22 \%$ atuavam em Marketing, 30\% em Administração geral, 35\% em Finanças e 13\% em Recursos Humanos. Assim, foi realizada uma análise time lag (TWENGE et.al, 2010) do comportamento das âncoras sob um enfoque das características da Geração Y. Tal análise permitiu a realização de comparações entre distintos membros desta geração, que estiveram em um mesmo estágio da vida, durante os quatro anos de duração da pesquisa

E importante enfatizar os cuidados éticos empreendidos na aplicação do questionário: a Coordenação do curso, ao longo dos anos, foi envolvida nas decisões quanto à abordagem dos respondentes e quanto à garantia do caráter voluntário do levantamento. Os pesquisadores mantiveram o compromisso formal quanto ao uso dos dados exclusivamente de maneira agregada e, rigorosamente, sem identificação individualizada dos participantes.

Foi realizada uma análise do comportamento das âncoras, sob o enfoque das características da Geração Y. No procedimento de análise dos dados, para atender o objetivo do estudo, foi realizada a divisão dos respondentes por gênero, utilizando a técnica estatística do teste $t$, que serve para avaliar a significância estatística da diferença entre duas médias de amostras independentes para uma única variável independente.

A divisão da atuação profissional dos pesquisados foi realizada por meio da análise de variância (Anova), que oferece maior flexibilidade no teste de diferença de grupos, pois proporciona ao pesquisador a possibilidade de testar diferenças em mais de dois grupos (HAIR et al, 2009). Neste caso, para avaliar as diferenças, foram empregadas comparações planejadas ou testes post hoc. O método de Scheffé foi utilizado por ser o mais conservador em relação ao erro Tipo 1. Ou seja, concluir que duas médias são significativamente diferentes quando, na verdade, são iguais (HAIR et al, 2009).

\section{Análise de dados e resultados da pesquisa}

Nesta seção os resultados são analisados e interpretados, iniciando-se pelo tipo de âncora, seguido da divisão entre os gêneros, finalizando com a profissão dos respondentes. 
No geral, a menor média das âncoras de carreira foi "Serviço e Dedicação a uma Causa" $(3,07)$, com desvio padrão de $(1,02)$ e, a maior, "Estilo de Vida" $(4,09)$, que apresentou desvio padrão de $(1,03)$. Para interpretar tal resultado, é importante resgatar as características dessas duas âncoras, conforme reflexões de Schein (1990).

Na âncora "Serviço e Dedicação a uma Causa", o indivíduo não abre mão de oportunidades de trabalho em que se realiza algo útil, como ajudar as pessoas, melhorar a harmonia entre elas ou solucionar problemas ambientais. Apesar da visão de que o jovem da Geração $Y$ "quer fazer a diferença no mundo" (LANCASTER; STILLMAN, 2011), é possível supor que a menor incidência nessa âncora se deve ao momento de conclusão do curso dos sujeitos pesquisados, pois, nessa fase, os jovens sofrem grande pressão social para construir sua independência financeira, formar sua identidade profissional e encontrar seu lugar na sociedade.

Por outro lado, a âncora "Estilo de Vida" envolve valores relacionados ao modo de viver que equilibra necessidades pessoais, familiares e exigências profissionais. A carreira, neste caso, deve ser flexível o suficiente para que tal equilíbrio aconteça. Pessoas da Geração Y, apreciadoras da liberdade (TASPSCOTT, 2009) preferem esquemas mais flexíveis de trabalho para se dedicarem aos seus objetivos pessoais (CENNAMO, GARDNER, 2008; ZEMKE; RAINES, FILIPCZAK, 2000), fato que confirma o resultado encontrado neste estudo. A análise dessa preferência por flexibilidade pode ser contraposta à visão de Bauman (2005), que afirma a necessidade humana de segurança, que leva a um anseio por identidade, relacionada ao sentido de pertencer.

Em complemento a essas análises, é importante verificar, na Tabela 1, a variação das âncoras ao longo dos anos.

Tabela 1. Variação das medias das âncoras de carreira de 2008 a 2011

\begin{tabular}{c|c|c|c|c|c|c|c|c}
\hline Ano & TF & GG & SE & CE & SD & AI & DP & EV \\
\hline \multirow{2}{*}{$\mathbf{2 0 0 8}$} & 3,82 & 3,89 & 3,66 & 3,85 & 3,04 & 4,00 & 4,15 & 4,09 \\
& $(0,98)$ & $(1,25)$ & $(1,16)$ & $(1,40)$ & $(1,17)$ & $(1,00)$ & $(1,09)$ & $(1,27)$ \\
\hline \multirow{2}{*}{$\mathbf{2 0 0 9}$} & 3,74 & 3,77 & 3,98 & 4,25 & 3,08 & 4,05 & 4,02 & 4,07 \\
& $(1,07)$ & $(1,10)$ & $(1,23)$ & $(1,50)$ & $(1,14)$ & $(1,08)$ & $(1,05)$ & $(1,38)$ \\
\hline \multirow{2}{*}{$\mathbf{2 0 1 0}$} & 4,10 & 4,07 & 3,73 & 4,11 & 3,02 & 4,28 & 4,14 & 4,08 \\
& $(1,02)$ & $(1,92)$ & $(1,24)$ & $(1,58)$ & $(1,34)$ & $(1,02)$ & $(1,09)$ & $(1,30)$ \\
\hline \multirow{2}{*}{$\mathbf{2 0 1 1}$} & 4,28 & 3,80 & 3,80 & 4,08 & 3,27 & 4,04 & 4,01 & 4,52 \\
& $(2,51)$ & $(1,09)$ & $(1,13)$ & $(1,56)$ & $(1,06)$ & $(1,15)$ & $(1,18)$ & $(1,40)$ \\
\hline Média & 4,07 & 3,93 & 3,76 & 4,07 & 3,07 & 4,00 & 4,08 & 4,09 \\
Geral & $(1,62)$ & $(1,52)$ & $(1,19)$ & $(1,53)$ & $(1,02)$ & $(1,31)$ & $(1,25)$ & $(1,03)$ \\
\hline
\end{tabular}

Nota: Desvio padrão entre parênteses 
Os resultados mostram que, durante os anos da pesquisa, não houve variação significativa $(\mathrm{p}<0,05)$ das médias gerais das âncoras, conforme teste post-hoc de Scheffé. Este resultado corrobora os achados de Kilimnik et al (2008) de que as âncoras de carreiras tendem a ser estáveis ao longo tempo.

\section{O gênero}

Especificamente em relação ao gênero, foram constatadas diferenças significativas $(\mathrm{t}=3,9 ; \mathrm{p}<0,05)$ apenas nas âncoras de Gerência Geral, Criatividade Empreendedora $(\mathrm{t}=4,4 ; \mathrm{p}<0,05)$ e Estilo de Vida $(\mathrm{t}=-3,5 ; \mathrm{p}<0,05)$. Já quando a comparação se dá ao longo do tempo, nota-se que a variação da média entre ambos permanece praticamente a mesma, conforme exposto nos Gráficos 3, 4 e 5, demonstrando certa estabilidade nas tendências de detecção das âncoras desses dois grupos.

Gráfico 3. Variação da âncora Gerencial Geral de 2008 a 2011

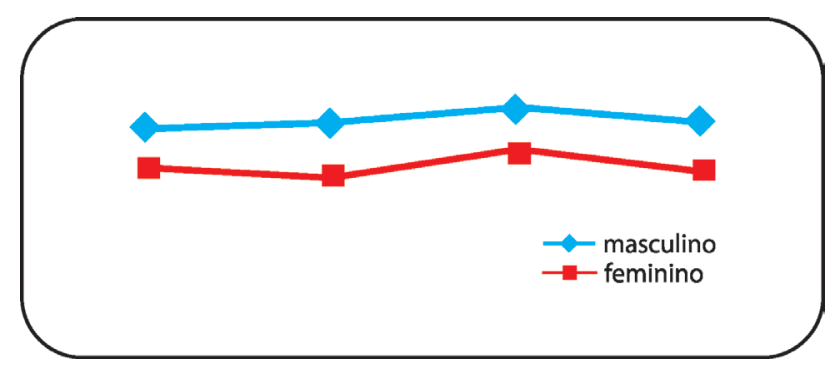

Fonte: elaborado pelos autores.

Gráfico 4. Variação da âncora Criatividade Empreendedora de 2008 a 2011

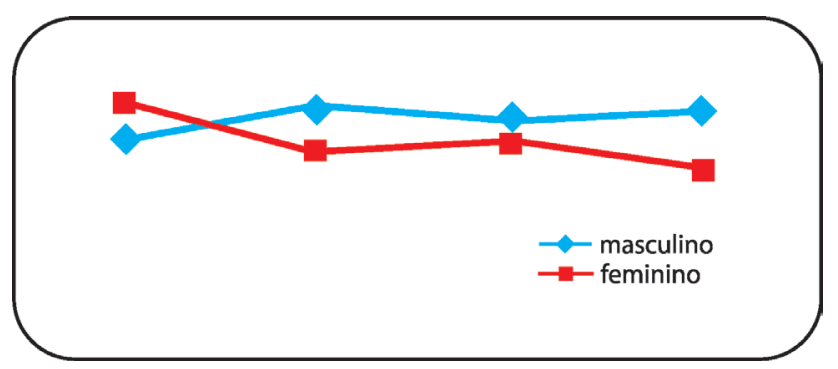

Fonte: elaborado pelos autores. 
Gráfico 5. Variação da âncora estilo de vida de 2008 a 2011

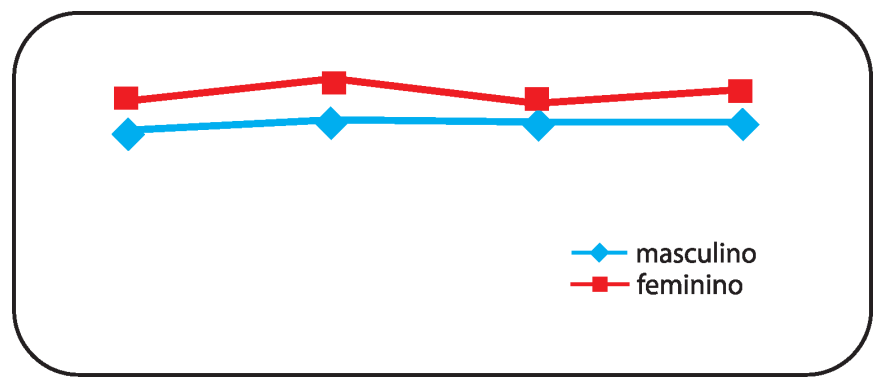

Fonte: elaborado pelos autores.

Por meio do teste estatístico foi possível constatar que esses dois grupos são diferentes em três âncoras. Os gráficos apresentados mostram a seguinte tendência: mulheres apresentam menor tendência a se identificarem com as âncoras "Competência Gerência Geral" e "Criatividade Empreendedora". Por outro lado, apresentam maior tendência a se enquadrar na âncora "Estilo de Vida". Para analisar esses resultados, é importante resgatar o fato de que pessoas enquadradas na âncora "Competência Gerência Geral" relacionam o seu sucesso profissional ao sucesso da organização, com responsabilidade absoluta por resultados. Já a âncora "Criatividade Empreendedora" envolve a disposição a assumir riscos na busca de oportunidades de criação empreendimentos (SCHEIN, 1990).

Um possível apoio à interpretação dos resultados obtidos nesta pesquisa é oferecido por Hoffman (2004), mas independe da geração. O autor aponta o fato de que homens são mais inclinados a correr riscos do que mulheres, que, por sua vez, são mais sensíveis ao universo simbólico e espiritual da espécie humana por sua finalidade reprodutiva e de conservação do desenvolvimento da vida. Essas reflexões, provavelmente, se relacionam também com a maior incidência da âncora "Estilo de Vida" entre as pesquisadas da Geração Y.

\section{A profissão}

No que diz respeito à ocupação profissional dos respondentes, dentre as oito âncoras analisadas, o teste post-hoc de Scheffe constatou diferença significativa $(\mathrm{p}<0,05)$ apenas na âncora "Criatividade Empreendedora" ( $\mathrm{F}=5,9$; $\mathrm{p}<0,05)$ nos quatro grupos. A maior diferença identificada foi das pessoas que atuavam na área de Recursos Humanos $(3,32)$ em comparação com as demais áreas: Marketing (4,0); Administração geral $(4,17)$; e Finanças $(4,36)$, esta última com a menor média, como pode ser observado no Gráfico 6 . 
Gráfico 6. Variação da âncora Criatividade Empreendedora de 2008 a 2011

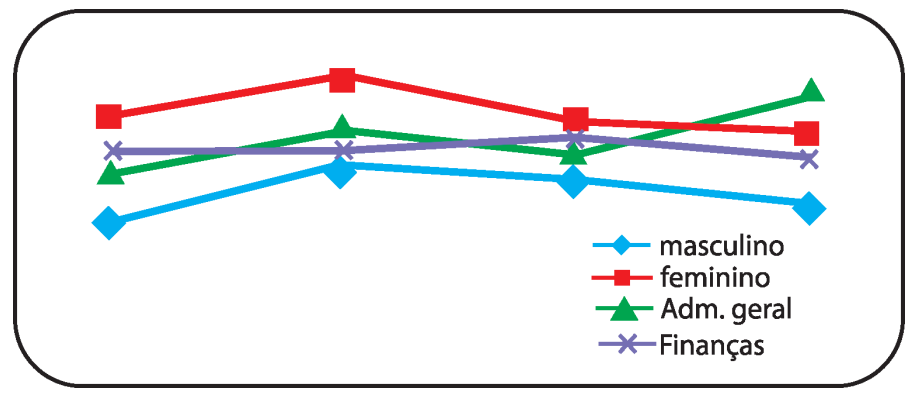

Fonte: elaborado pelos autores.

Conforme mencionado na análise das diferenças entre gêneros, a âncora "Criatividade Empreendedora" se relaciona com a criação da própria organização. Pessoas enquadradas nesta âncora enxergam seu êxito financeiro no empreendedorismo como prova de capacidade profissional (SCHEIN, 1990). Para entender os resultados deste estudo é importante resgatar o a tendência apontada por Dutra (2010) de que pessoas permaneçam em atividades profissionais de mesma natureza, o que deve explicar a tendência futura dos jovens da Geração Y, por meio da identificação de sua âncora.

Os resultados aqui apresentados mostram a diferença entre os profissionais de Recursos Humanos em relação aos de outras áreas. Nota-se, então, que os que atuam em gestão de pessoas tendem a buscar a construção da sua trajetória mais atrelada a organizações já existentes, enquanto os de Marketing, Administração geral e os de Finanças tendem a procurar atividades mais independentes.

\section{Considerações finais}

Os resultados aqui apresentados sinalizam evidências da proposta de Ibarra (2009) sobre níveis de critérios para decisão de carreira, em consonância às âncoras de carreira dos indivíduos. Nesse sentido, podemos classificar, como nível mais visível, a atual ocupação profissional no quesito âncora de "Criatividade Empreendedora". Os resultados apresentados mostraram que os respondentes que atuam na área de Recursos Humanos são menos propensos a essa âncora, em comparação aos respondentes de outras áreas da Administração.

Transferindo as reflexões sobre a capacidade empreendedora de formação de novos negócios para as atividades internas à organização, é possível promover a discussão sobre o quanto os profissionais de Recursos Humanos 
da Geração Y apresentam predisposição a inovações em produtos e serviços. Desta forma, apesar dos apelos de que a Geração Y é mais independente da organização do que as anteriores, nota-se que dentro da trajetória profissional escolhida certas particularidades devem ser consideradas. Os profissionais que voltam sua trajetória à área de Finanças, por exemplo, devem receber estímulos que considerem sua tendência ao empreendedorismo.

Constatamos que entre os membros da Geração Y existem diferenças conforme o gênero do respondente, existindo diferenças significativas em relação às âncoras "Gerencial Geral" e "Criatividade Empreendedora", com resultados mais elevados para os homens. As mulheres, por sua vez, apresentaram resultados mais elevados na âncora "Estilo de Vida", provavelmente devido à necessidade e pressão pelo balanceamento entre vida pessoal e carreira nas organizações. É importante enfatizar o fato de que esses resultados estão alinhados aos resultados encontrados por Schein (1996). Em uma visão prática, a diferença de gênero é evidente e não pode ser desconsiderada pelos gestores de pessoas das organizações ao buscarem o engajamento das pessoas da Geração Y.

Por fim, no que corresponde às premissas básicas ou mapa mental dos membros da Geração Y, encontramos que, no geral, a âncora "Estilo de Vida" dirige o comportamento das pessoas dessa geração, o que corrobora os achados de Vasconcelos et al (2009). Outro ponto que merece maior aprofundamento em estudos futuros é o menor índice na âncora "Serviço e Dedicação a uma Causa".

A partir da noção de gerações ativas e passivas de Edmunds e Turner (2005), podemos sugerir que a Geração Y possui características de geração ativa por ser mais aderente à âncora "Estilo de vida"; assim, a busca por equilíbrio entre vida e trabalho dessa geração, conforme apontada pela literatura (TWENGE et al , 2010), seria o impacto mais evidente no cotidiano das organizações. Ao mesmo tempo, por ser menos aderente à âncora "Serviço e Dedicação a Uma Causa", também podemos questionar o quanto os indivíduos dessa geração estão preocupados em se engajar a um objetivo de vida, transformação da sociedade ou do mundo do trabalho.

Acreditamos que uma contribuição deste estudo à gestão de pessoas das organizações consiste na associação das âncoras aos estudos sobre Geração $\mathrm{Y}$, o que pode ajudar gestores a entenderem as particularidades desses jovens que influenciam fortemente o mercado de trabalho atual. A limitação consiste no fato de que os pesquisados eram formandos no curso de Administração, enquanto os profissionais na Geração $Y$ atuantes no mercado têm formações diversas. Tendo em vista a atualidade do tema e seus desdobramentos, vale ressaltar que estudos futuros com formandos de outros cursos são oportunos, e que venham a se somar aos de outros pesquisadores brasileiros (DUTRA, 1996; BASTOS, 1997; KILIMNIK, 1999; FERRAZ, 2005; BALASSIANO e COSTA, 2006; OLTRAMARI, 2008). 


\section{Agradecimento}

\section{Pelo apoio e financiamento da PROGEP-FIA e CNPQ.}

\section{Referências bibliográficas}

ARTHUR, Michael B.; HALL, Douglas T.; LAWRENCE, Barbara. S. Preface. In: ARTHUR, M. B.; HALL, D. T. \& LAWRENCE, B. S. (Eds.) Handbook of career theory. New York: Cambridge University Press, 1989.

ARTHUR, Michael B.; ROUSSEAU, Denise M.The Boundaryless Career: A New Employment Principle for a New Organizational Era. New York: Oxford University Press, 1996.

ARTHUR, Michael B.; CLAMAN, Priscilla H.; DeFILLIPPI, Robert J. Intelligent enterprise, intelligent careers. Academy of management executive, [S.1.], v.9, n.4, 1995.

BALASSIANO, Moisés; COSTA, Isabel de Sá Affonso da. Gestão de Carreiras: Dilemas e Perspectivas. São Paulo: Atlas, 2006.

BASTOS, Antônio Virgílio B. A escolha e o comprometimento com a carreira: um estudo entre profissionais e estudantes de Administração. Revista de Administração, São Paulo, v. 32, n.3, p.28-39, jul./set.1997.

BAUMAN, Z. Identidade: entrevista a Benedito Vecchi. Rio de Janeiro: Jorge Zahar Ed., 2005.

CABRAL, Eliane S. de Mattos; KILIMNIK, Zélia Miranda; VELOSO, Elza Fátima Rosa.. Fatores Condicionantes da Atração e Retenção de Jovens Profissionais e âncoras de Carreira: Um Estudo com engenheiros Recém-Formados de uma Empresa Construtora de Obras de Infraestrutura de Minas Gerais. In: ENCONTRO DA ANPAD-EnANPAD, 37, 2013. Rio de Janeiro. Anais... Rio de Janeiro: ANPAD, 2013.

CENNAMO, Lucy; GARDNER, Dianne. Generational differences in work values, outcomes and person-organization values fit. Journal of Managerial Psychology, [S.1], v. 23, n. 8, p. 891906, 2008.

CHANLAT, Jean-François. Quais carreiras e para qual sociedade? Revista de Administração de Empresas, São Paulo, v. 35, n., p. 67-75, jan./mar. 1995.

COELHO, Joyce Ajuz. Organizações e carreiras sem fronteiras. In: BALASSIANO, Moisés e COSTA, Isabel S. A. Gestão de Carreiras: dilemas e perspectivas. São Paulo: Atlas, 2006. p. 94-108.

COIMBRA, R. G. C. \& SCHIKMANN, R. A geração net. In: ENCONTRO DA ANPAD-EnANPAD, 25, 2001, Campinas. Anais... Campinas: ANPAD, 2001.

DUTRA, Joel Souza. Trajetórias de carreira nas organizações. In: DUTRA, Joel Souza. (Org). Gestão de carreiras na empresa contemporânea. São Paulo: Atlas, 2010.

.Administração de carreiras: uma proposta para repensar a gestão de pessoas. São Paulo: Atlas, 1996. 
Carreiras paralelas: uma proposta de revisão da administração de carreiras. Revista de Administração, São Paulo, v. 27, n.4, p. 65-73, out./dez.1992.

EDMUNDS, J.; URNER, B. Global generations: social change in the twentieth century. British Journal of Sociology, [S.1], v. 56, n. 4, p. 559-577, dez. 2005.

FERRAZ, Serafim F. de S. et al. Análise da formação em Administração na perspectiva das inclinações profissionais, Brasília. In: ENCONTRO DA ANPAD-EnANPAD 29, 2005, Brasília. Anais... Brasília: ANPAD, 2005.

GIL, Antônio Carlos. Métodos e técnicas de pesquisa social. São Paulo: Atlas, 1999.

GOMES, A. F. O outro no trabalho: mulher e gestão. Revista de Gestão USP, São Paulo, v.12, n. 3, p. 1-9, jul./set. 2005.

HALL, Douglas T. Careers in and out of organizations. London: Sage Publications, 2002.

HIRATA, H. Reestruturação produtiva, trabalho e relações de gênero. Revista Latino-Americana de Estudios del Trabajo, São Paulo, v. 4, n. 7, p. 5-17, 1998.

HOFFMANN, Gleise H. Responsabilidade social e a questão de gênero. Revista Fae Business, Curitiba, $\mathrm{n}^{\circ} 9$, set. 2004.

HUGHES, Everett C.; COSER, Lewis. A. (Ed.). On work, race, and the sociological imagination. Chicago: University of Chicago Press, 1994.

IBARRA, Hermínia. Identidade de carreira: a experiência é a chave para reinventá-la. São Paulo: Gente, 2009.

INSTITUTO BRASILEIRO DE GEOGRAFIA E ESTATÍSTICA. Pesquisa Mensal de Emprego - PME. Mulher no mercado de trabalho: perguntas e respostas. IBGE, mar. 2012. Disponível em: $<$ http: //www.ibge.gov.br>. Acesso em: 07 abr. 2012.

KILIMNIK, Zélia Miranda. Transição de Carreiras Profissionais no Atual Contexto Competitivo e de Redução de Empregos. In: ENCONTRO DA ANPAD-EnANPAD, 23, Foz do Iguaçu. Anais.... Foz do Iguaçu: ANPAD, 1999.

LANCASTER, Lynne C.;S TILLMAN, David. O Y da questão: como a geração Y está transformando o mercado de trabalho. São Paulo: Saraiva, 2011.

LIPKIN, Nicole; PERRYMORE, April. A Geração Y no Trabalho: como lidar com, a força de trabalho que influenciará definitivamente a cultura da sua empresa.Rio de Janeiro: Elsevier, 2010 .

LONDON, M.; STUMPH, S. Managing careers. Massachussetts: Addison-Wesley, 1982.

MARTIN, Carolin A.; TULGAN, Bruce. Managing the generation mix: from urgency to opportunity. Amherst, Massachusetts: HRD Press, 2006.

NEVES, Magda de Almeida. As novas configurações do trabalho: diversidade, precarização e dominação. In: ZEBALLOS, Eliseo; SANTOS, José Vicente Tavares; FIGUEREDO, D. 
GOMES, Dione F. N. et al. Contribuição das âncoras de carreira para entender diferenças e...

(Org). América Latina: hacia uma nueva alternativa de desarrollo. Arequipa, Peru: Unsa, 2004. p.186-199

OLTRAMARI, Andrea Poleto. Carreira: panorama de artigos sobre o tema. In: ENCONTRO DA ANPAD-EnANPAD, 32, Rio de Janeiro. Anais... Rio de Janeiro: ANPAD, 2008.

QUINN, James Brian. Inteligent enterprise: a knowledge and service based paradigm for industry New York: The Free-press, 1992.

RIBEIRO, Marcelo Afonso. A trajetória de carreira como construção teórico-prática e a proposta dialética da carreira psicossocial. Cadernos de psicologia social do trabalho, São Paulo, v. 12, n. 2, p. 203-216, 2009.

ROBBINS, Stephen P. Comportamento Organizacional. 11 a edição. São Paulo: Pearson Prentice Hall, 2006.

SANTOS, Neusa M. B. dos Santos; ABRAHIM, Gisele Seabra. A influência dos valores pessoais na determinação das âncoras de carreira. In: ENCONTRO DAANPAD-EnANPAD, 32, Rio de Janeiro. Anais... Rio de Janeiro: ANPAD, 2008.

SCHEIN, Edgar H. Career Anchors: Discovering Your Real Values. San Francisco: Jossey -Bass, 1990.

Identidade profissional: como ajustar suas inclinações a suas opções de trabalho. São Paulo: Nobel, 1996.

SMOLA, Karen Wei; SUTTON, Charlotte D. Generational differences: revisiting generational or values for the new Millennium. Journal of Organizational Behavior, [S.1], v. 23, n.4, p. 363382, jun. 2002.

TAPSCOTT, Don. Grow up digital: How the net generation is changing your world. New York: McGraw-Hill, 2009.

TWENGE, Jean M. et al. Generational differences in work values: Leisure and extrinsic values increasing, social and intrinsic values decreasing. Journal of Management, [S.1.], v.36, n.5, p.1117-1142, mar. 2010 .

UNIVERSIDADE DE SÃO PAULO. Ancoras de Carreira. Texto adaptado por DUTRA, Joel S. e ALBUQUERQUE, Lindolfo G. Albuquerque] São Paulo: USP, 2002. Mimeografado.

VASCONCELOS, K. C. A. et al. A Geração Y e Suas Âncoras de Carreira. In: Encontro de Gestão de Pessoas e Relações de Trabalho - EnGPR, 2, 2009, Curitiba. Anais do $2^{\circ}$ Engpr. Curitiba: ANPAD, 2009.

VELOSO, Elza Fátima Rosa; DUTRA, Joel S. Processo de transição de carreira. In: DUTRA, J. S. (Org). Gestão de carreiras na empresa contemporânea. São Paulo: Atlas, 2010.

VELOSO, Elza Fátima Rosa; SILVA, Rodrigo C.; DUTRA, Joel S. Gerações e Carreira: A Relação entre as Percepções sobre Carreiras Inteligentes e sobre Crescimento Profissional nas Organizações. In: ENCONTRO DA ANPAD-EnANPAD, 35, Rio de Janeiro. Anais...Rio de Janeiro: ANPAD, 2011. 
VIEIRA, Josênia Antunes. A identidade da mulher na modernidade. Delta, São Paulo, v. 21, n. Spe, p.207-238, 2005

WAINBERG, S. Experiências e Vivências de auxiliares de enfermagem do sexo masculino no exercício de uma profissão majoritariamente feminina. Dissertação (Mestrado em Psicologia Social e Institucional) Instituto de Psicologia, Universidade Federal do Rio Grande do Sul, Porto Alegre 2004.

ZEMKE, Ron; RAINES, Claire; FILIPCZAK, Bob. Generations at work: Managing the clash of veterans, boomers, xers, and nexters in your workplace. Nova York: AMACOM, 2000.

Recebido em: 07/5/2013

Revisão em: 01/09/2013

Aceite em: 08/10/2013

Dione Fagundes Nunes Gomes é Doutoranda e professora na Pontifícia Universidade Católica de São Paulo. Endereço para correspondência: R. Monte Alegre, 984. Perdizes, São Paulo/SP, Brasil. CEP 05014-901. E-mail: dfngomes@pucsp.br

Leonardo Nelmi Trevisan é Doutor em Ciência Política pela Universidade de São Paulo. Professor do Programa de Estudos Pós Graduados em Administração da PUC/SP. E-mail: lntrevisan@pucsp.br

Elza Fátima Rosa Veloso é graduada, mestre e doutora em administração. Doutorado sanduíche FEA-USP/Northern Illinois University e pós doutorado em andamento pela FEA-USP, com auxílio da FAPESP. É professora do PPGA das Faculdades Metropolitanas Unidas. No PROGEP-FIA, é professora e coordenadora executiva. É também professora da pós-graduação lato sensu da Universidade Presbiteriana Mackenzie. E-mail: elzafr@uol.com.br

Rodrigo Cunha da Silva é Doutor em administração pela Universidade de São Paulo e professor da Faculdade FIA Administração e Negócios. Atua em temas relacionados à gestão de carreira, gerações e ambiente de trabalho. E-mail: rdgcdasilva@gmail.com 